\title{
Gestão dos espaços naturais de Manaus: uma interpretação da sensibilização e participação pública na conservação de áreas protegidas
}

\author{
António Ribeiro da COSTA NETO ${ }^{1}$, Julio Rodríguez TELLO ${ }^{2}$, Lizit Alencar da COSTA ${ }^{3}$, Álefe Lopes \\ VIANA ${ }^{4}$, Jhones Lemos ALVES 5 , Ricardo BUHRING ${ }^{6}$
}

\begin{abstract}
RESUMO
O crescimento demográfico da população de Manaus, principalmente a partir da metade do século XX, pressionou a ocupação de novos espaços com o uso, exploração, descaracterização, fragmentação e sub-fragmentação da paisagem e, em alguns casos, até a destruiçấo da mesma. O envolvimento e a participação das comunidades do entorno das áreas protegidas, é fundamental em qualquer modelo ou plano de gestão. Com o objetivo de identificar e avaliar o grau de participaçáo da população local no contexto da proteçáo dessas áreas, adotou-se procedimentos metodológicos exploratórios por intermédio de pesquisas qualitativa e quantitativa de abrangência sócio-natural. Em regióes próximas a cinco unidades de conservação situadas em locais estratégicos e de distintas categorias de manejo, a interpretação foi realizada utilizando as técnicas de percepção ambiental e a representação social. Dos resultados da pesquisa, pode-se inferir que os níveis de participação através das representaçôes sociais, refletem os conflitos existentes entre o homem e a natureza, fortemente influenciados pelos níveis de escolaridade, faixa etária, estratificaçáo social e percepçáo ambiental dos sujeitos da pesquisa sobre o meio em que compartilham suas diversas relaçóes. Os cenários atuais, tendencial e normativo das paisagens naturais, modificadas ou mesmo organizadas da área de estudo, quando observados e analisados sob uma ótica investigativa, refletem essas diversas relaçôes "in naturas" que vêm ocorrendo de forma dinâmica e com elevadíssimo grau de intensidade e rapidez, traduzida na violenta fragmentação dos ecossistemas naturais pela ação antrópica.
\end{abstract}

PALAVRAS-CHAVE: áreas protegidas, conservação ambiental e representação social.

\section{Management of naturals of Manaus: an interpretation of sensibilization and public participation in conservation of protected areas}

\begin{abstract}
The demographic growth of Manaus, mainly since mid-twentieth century, has pressured the occupation of new spaces with the use, exploration, discharacterization, spalling and sub-spalling of the landscape and, in some cases, its very destruction. Involvement and=participation by communities of surrounding and protecting areas are basic to any model or plan of management. With the objective of identifying and evaluating the degree of participation by the local population, in the context of protecting these areas, we adopted exploratory inquiry procedures through qualitative and quantitative intermediary research=to take in the social and natural areas. In regions close to five situated units of conservation in strategical places and of distinct management categories, our interpretation was archived using techniques of environmental perception and social representation. It can be inferred from the results that the levels of participation by social representation reflect the existing conflicts between man and nature. This is influenced strongly by formal education, age, social stratification and environmental perception of the subjects of this research. The current scenarios, legislative trend of natural or modified landscapes, or even those not in our study area, when observed and analyzed from an investigative perspective, reflect these various relationships in nature that are occurring in a dynamic way and with high degree of intensity and speed, and translate into violent fragmentation of natural ecosystems by human action.
\end{abstract}

KEYWORDS: protected areas, environmental conservation and social representation.

\footnotetext{
1 Universidade Federal do Amazonas. E-mail: arcneto@uol.com.br

2 Universidade Federal do Amazonas. E-mail: jtello@ufam.edu.br

3 Universidade Federal do Amazonas. E-mail: Icosta@ufam.edu.br

${ }^{4}$ Universidade Federal do Amazonas. E-mail: alefe.viana@gmail.com

${ }^{5}$ Universidade Federal do Amazonas. E-mail: jhonlemos7@gmail.com

${ }^{6}$ Universidade Federal do Amazonas. E-mail: ricardoflorestal@hotmail.com
} 


\section{INTRODUÇÃO}

A reflexão em torno das práticas sociais num contexto urbano marcado pela deterioração permanente do ambiente construído e do seu ecossistema, não pode prescindir nem da análise dos fatores determinantes do processo e nem dos atores envolvidos e das formas de organizaçáo social, que potencializam novos desdobramentos e alternativas de ação numa perspectiva de sustentabilidade.

A noção de sustentabilidade, por sua vez, implica em uma necessária inter-relaçáo entre justiça social, qualidade de vida, equilíbrio ambiental e a necessidade de um desenvolvimento, respeitando a capacidade de suporte dos ambientes (Hogan 1993), sejam estes construídos ou naturais.

No contexto urbano metropolitano brasileiro, os problemas ambientais têm se avolumado a passos gigantescos e a sua lenta resolução tem se tornado de conhecimento público pela virulência dos seus impactos.

Esses cenários não se configuram como exceçôes para a cidade de Manaus. Haja vista que o crescimento demográfico da sua população, principalmente a partir da segunda metade do século XX, pressionou a ocupação de novos espaços com o uso, exploração, descaracterização, fragmentação e subfragmentaçáo da paisagem e, em alguns casos, até a total eliminação da mesma.

A passagem pela compreensão dos problemas ambientais, de uma ótica mais centrada nas ciências naturais, para um escopo mais abrangente sobre o tema, inclui necessariamente o componente social.

É nessa ótica de pensamento investigativo sobre o comportamento social diante dos fenômenos do cotidiano que, segundo Reigota (2002), podem-se reportar as premissas da Teoria da Representação Social, baseadas nas reflexóes de Serge Moscovici, no âmbito da Psicologia Social, datadas de 1961.

As representaçóes sociais estão muito além do que imaginamos, quando associamos o termo "representação social" a uma questão meramente político-partidária, mas refere-se ao estudo da percepçáo e do senso comum que cada ser ou grupo social possui diante de um determinado tema (Moscovici 2003).

Para Piaget (1969), "nem tudo o que envolve a inteligência passa pelos sentidos". A mente humana organiza e representa uma dada realidade percebida através de esquemas perceptivos e imagens mentais, com atributos específicos: realidade local $=>$ sensaçóes $=>$ motivação $=>$ cognição $=>$ avaliação $=>$ conduta social.

Wagner (1995) revelou que o envolvimento e a participação das comunidades do entorno das áreas protegidas deverá ser condição primordial na elaboração e execução em qualquer modelo ou plano de gestão. As preocupaçóes populares constituem uma salvaguarda contra as decisóes apressadas do poder público e do espírito ganancioso do mercantilismo local, e um meio indispensável para levar ao conhecimento da populaçáo, a importância e os problemas enfrentados nas ações de conservação dos ambientes naturais. A participação reforça a confiança pública e melhora a internalização dos objetivos principais da gestáo, oferece dados adicionais aos planejadores e administradores responsáveis pelas políticas públicas, e incentiva o envolvimento da comunidade local na proteção da área.

Com base nos fundamentos expostos anteriormente, este estudo objetivou identificar e avaliar o nível de participação da populaçấo local na gestấo de áreas protegidas em Manaus, a fim de contribuir para a compreensão da importância da proteçáo dos espaços naturais, sejam estes legalmente protegidos ou não.

\section{MATERIAL E MÉTODOS}

O material utilizado para a execuçáo deste estudo constou da consulta em bibliografias gerais, especializadas e complementares, além da elaboração de roteiros de entrevistas, formulários e questionários.

Seguindo as recomendaçóes de Barros e Lehfeld (2004), quanto à necessidade de se selecionar parcelas ou partes de um todo para aplicação de um determinado método, neste estudo, foram selecionadas 5 (cinco) unidades amostrais que seguiram critérios do tipo não-probabilísticos e intencionais atendendo aos seguintes aspectos: os grupos de proteção e categorias de manejo; localização e viabilidade no acesso; infra-estrutura disponível e finalmente, áreas protegidas com potencial de risco de pressão antrópica.

As unidades selecionadas foram: Parque Municipal do Mindu, Jardim Botânico de Manaus Adolfo Ducke, Refúgio da Vida Silvestre Sauim-Castanheiras, Área de Relevante Interesse Ecológico do Campus da Universidade Federal do Amazonas (UFAM), todas localizadas no perímetro urbano do Município de Manaus, e Reserva de Desenvolvimento Sustentado do Tupé, a única localizada na área rural do Município.

Quanto aos métodos e instrumentos de coleta de dados utilizados, dada a importância atribuída ao contexto nas pesquisas sócio-naturais, o processo investigatório foi precedido por um período exploratório onde foram focalizadas as instituiçóes e seus procedimentos para acesso a determinados espaços, documentos e dados. No caso da pesquisa aplicada em comunidades, esta etapa culminou na identificação das principais lideranças locais, essenciais para obter acesso aos demais participantes da pesquisa. Segundo Alves-Mazzotti e Gewandsznajder (2001), a finalidade do período exploratório é a obtenção de informaçôes suficientes 
sobre os canais de acesso que irão balizar as decisóes iniciais sobre as questôes relevantes ao design do estudo, às observaçôes, impressôes e insights das unidades amostrais.

Definido os contornos da pesquisa, passou-se à etapa da investigaçáo focalizada na coleta sistemática de dados. Enquanto no período exploratório, o pesquisador conta apenas com seu "poder de observação" (uso dos sentidos), nesta fase recorreu-se aos instrumentos auxiliares da pesquisa qualitativa e quantitativa como questionários, roteiros de entrevistas e/ ou formulários de observação.

A partir daí, foi delimitada como zona de pressão e influência antrópica o raio de $1 \mathrm{~km}$ do perímetro de cada uma das unidades amostrais selecionadas, onde foi realizada a maior parte da aplicação dos instrumentos da pesquisa.

Nesta fase da pesquisa, procurou-se avaliar o nível de participação da populaçáo que reside no entorno dessas unidades de conservação, bem como dos seus visitantes, nas diversas açôes em que os poderes públicos instituídos venham a implementar nessas áreas, visando à proteção das mesmas, além de avaliar o comprometimento comunitário na proteçáo das respectivas áreas, através de técnica de amostragem piloto (aplicação de questionários de percepção ambiental).

Dentre os diversos métodos utilizados na seleção dos participantes, optou-se pelo da representação social que, segundo Moscovici (2003), é o mais adequado para a abordagem, de forma articulada, dos aspectos de natureza psicológica e sociológica dos participantes.

A aplicação dos questionários foi direcionada aos membros de associaçóes comunitárias e/ou moradores, alunos e professores das unidades escolares de ensino fundamental, médio e superior, público visitante das unidades de conservação, representantes do segmento empresarial e ocupantes de cargos e funçôes políticas locais.

O encerramento da coleta de dados em pesquisas qualitativas deu-se a partir do momento em que as informaçôes já obtidas, estavam sendo suficientemente confirmadas por meio de uma curva de correlação, e que o surgimento de novos dados ia ficando cada vez mais raro. Este momento é chamado de "ponto de redundância" a partir do qual não se justifica a inclusấo de novos elementos (Lincoln e Guba 1985).

A análise e interpretaçáo dos dados de um processo exploratório/investigatório, segundo Lakatos e Marconi (2001), representa a aplicação lógica dedutiva e indutiva da pesquisa em si.

Neste caso, procurou-se apresentar os fatos com referência analítica às inferências oriundas na interpretação qualitativa e quantitativa das respostas dos questionários aplicados, retratando fielmente o nível de percepção da sociedade local sobre a questão ambiental.

\section{RESULTADOS E DISCUSSÃO}

Com base no ponto de redundância da curva de correlação encontrado, foram validados 3.597 questionários, aplicados no período de outubro de 2004 a junho de 2005 , totalizando 50.358 perguntas, divididas em três grupos. O primeiro grupo de perguntas visava à identificação dos participantes participação dos gêneros, faixas etárias, níveis de escolaridade, categorias sociais e localização geopolítica no Município de Manaus. O segundo grupo, tinha por finalidade extrair o conhecimento dos entrevistados sobre os conceitos ou significados de ambiente, e de áreas naturais protegidas ou unidades de conservação, estabelecendo paralelos entre suas respostas e os exemplos e indicaçóes sobre os problemas ambientais de Manaus citados por eles. E, o terceiro e último grupo de perguntas esteve referida à participação social na gestão ambiental pública.

\section{Perfil dos Entrevistados}

Do universo de entrevistados, obteve-se uma participação masculina em 1.295 questionários (36\%), enquanto que a participação feminina foi de 2.302 entrevistas (64\%). Este fato deveu-se principalmente, a parcela da população feminina ser encontrada nas residências durante períodos diurnos, além de uma maior receptividade à participação na pesquisa.

Quanto às faixas etárias identificadas, observou-se que a pesquisa atingiu intervalos de idades bastante amplos, concentrando os maiores índices de participação (62,5\%) entre 21 a 40 anos.

Outro aspecto observado foi que na medida em que se distanciava geograficamente das zonas do Município de Manaus de maior concentração de renda, o nível de escolaridade das pessoas entrevistadas também ia sofrendo uma diminuição bastante perceptível. Em algumas situaçôes, esse aspecto até chegou a dificultar o processo de entrevista, pela morosidade na compreensão das perguntas.

Na Figura 1, apresenta-se a participação da sociedade por zona geopolítica do Município de Manaus.
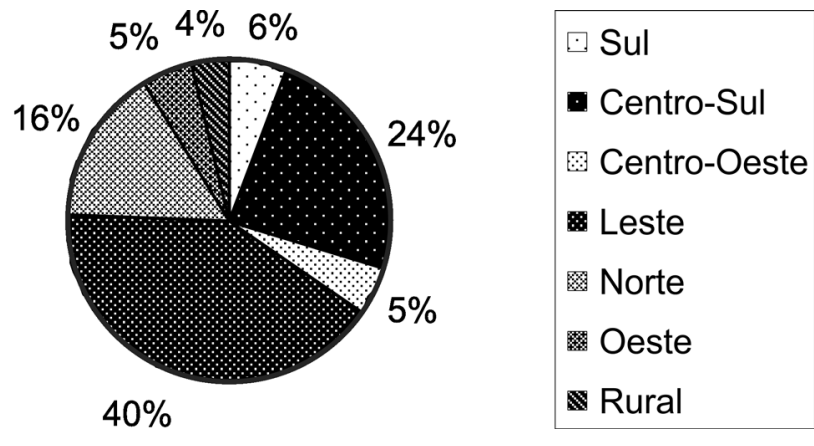

Figura 1 - Participação pública por zonas geopolíticas de Manaus. 
Dentro do universo, inicialmente proposto, observou-se uma participaçáo de segmentos da sociedade, um pouco além do que se esperava. Porém, é inegável a contribuição estudantil nas entrevistas, em seus diversos níveis de escolarização, com um percentual de 59,9\% de participação (Figura 2).

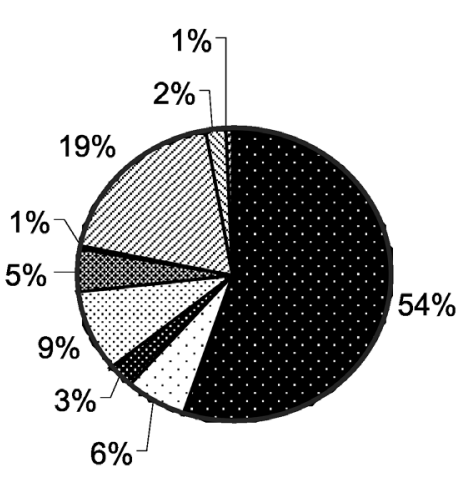

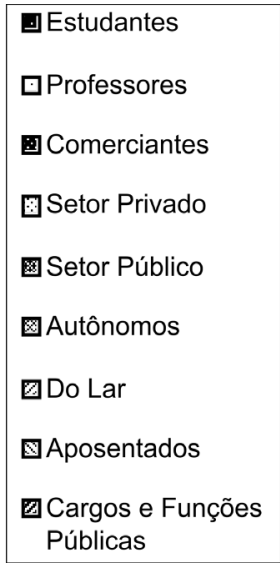

Figura 2 - Categorias de representação dos entrevistados.

Quanto à caracterização sobre a origem dos entrevistados, dividiu-se em dois grupos. Um grupo destinado apenas aos visitantes das unidades de conservação selecionadas, cujas categorias de manejo se permite somente à visitação pública, tais como Parque Municipal do Mindu e Jardim Botânico de Manaus, incluindo a Reserva de Desenvolvimento Sustentável do Tupé, que concentra a maior taxa de visitação/mês dentre as unidades de conservação de Manaus. Juntas essas áreas totalizaram 537 pessoas entrevistadas (14,9\%). No grupo destinado aos moradores e freqüentadores do entorno ou das áreas de influência das unidades de conservaçấo (Parque Municipal do Mindu, Jardim Botânico de Manaus Adolpho Ducke, Refúgio da Vida Silvestre Sauim-Castanheiras e Área de Relevante Interesse Ecológico do Campus da UFAM, incluindo novamente a do Tupé - cuja categoria de manejo permite esse tipo de concessão pública no interior da Reserva) a participaçáo foi de 3.060 pessoas $(85,1 \%)$.

\section{Conhecimentos sobre Ambiente e Unidades de Conservação}

Nessa etapa da pesquisa, procurou-se conhecer o saber local quanto aos diversos conceitos e significados de Ambiente, utilizando-se para isso perguntas não-estruturadas ou livres. Do universo pesquisado, 1.325 entrevistados $(36,8 \%)$ disseram ou escreveram que ambiente ou meio ambiente representa "o cuidado com a Natureza"; para 629 dos entrevistados (17,5\%), significa "proteger a fauna e a flora"; 578 entrevistados $(16,1 \%)$, quer dizer o "conjunto de todos os seres vivos na Terra"; 413 pessoas $(11,5 \%)$ disseram ou escreveram que é o "lugar onde vivemos"; para 358 entrevistados (10\%) significa apenas "preservar os animais";
259 pessoas $(7,2 \%)$ responderam que está relacionado com a "conservaçáo de áreas naturais"; e, 35 do total dos entrevistados (1\%), não opinaram ou não souberam responder (Figura 3).
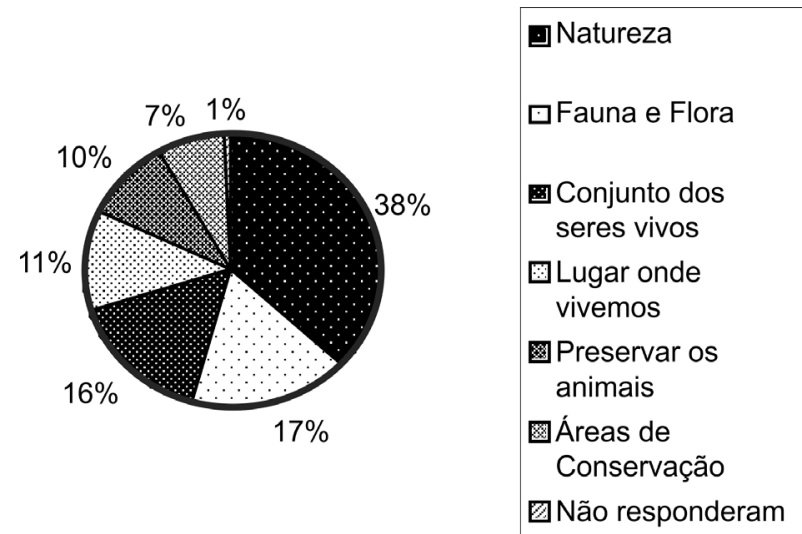

Figuras 3 - 0 significado de Ambiente para a população entrevistada.

Observa-se nas respostas obtidas, uma tendência de redução do conceito de ambiente a uma denominação "naturalista" pelas representaçóes sociais (83\%), por intermédio da percepção de territorialidade (espaço físico), da sua constituição (componentes bióticos e abióticos) e de conservacionismo. Ainda é bastante expressiva a exclusão total do homem do conceito de Ambiente. Isso pode ser facilmente comprovado pelo reflexo dos valores intrínsecos a cada cidadão atribuídos ao mesmo. Essas visōes de uma Natureza intocada e de um Ambiente excludente dos diversos atores sociais refletem os primeiros impulsos a indagaçóes desse tipo, e confirmam os estudos sobre a representação social da psicanálise na populaçáo do entorno da cidade parisiense em fins dos anos cinqüenta do século XX por Moscovici (1978).

Porém, na questâo seguinte esse quadro é invertido, pois quando perguntado ao universo dos entrevistados se concordavam que o Ser Humano também fazia parte do Ambiente, 2.229 pessoas (62\%) afirmaram que "sim", 1.249 $(34,7 \%)$ responderam que "náo" e 119 (3,3\%) "náo opinaram ou não souberam responder".

É claro que esse tipo de atributo de valor aos Ambientes Naturais e Sociais é fortemente influenciado pelos fatores intrínsecos (herança histórico-cultural, preconceitos, ideologias, patrimônio genético, escolaridade, aspectos psicológicos etc.) que compóem a formação humanista, mas sem descartar o quadro sócio-político-econômico em um dado momento.

Moscovici (1978) estabeleceu que a estrutura das representaçóes sociais, se configura ao longo de três dimensóes: da informaçáo, do campo de representaçáo e da açáo ou atitude. A informação "se refere à organização dos conhecimentos que um grupo possui a respeito de um objeto social". O campo de 
representaçáo "remete à idéia de imagem, de modelo social, ao conteúdo concreto e limitado das proposiçóes acerca de um aspecto preciso do objeto da representaçáo". A açấo ou atitude "termina por focalizar a orientação global em relação ao objeto da representação social".

Então, nesse caso específico, o tipo de informação que essas pessoas receberam ao longo de suas vidas com essa perspectiva holística sobre Ambiente, seja por meio de um processo educativo formal e/ou informal, influenciou fortemente na reproduçáo e multiplicação dos conceitos e dos valores atribuídos. Nota-se que mais da metade dos entrevistados (62\%), atribui ao ser humano como "parte de" um todo (o Ambiente), muito contrastante com a resposta da pergunta anterior $(16,1 \%)$. Isso se deve a certos conceitos e valores que muitas vezes se encontram adormecidos no subconsciente humano e que bastam um indicativo qualquer para se tornarem claros.

$\mathrm{Na}$ pergunta a respeito sobre o significado de Áreas Naturais Protegidas ou de Unidades de Conservação, apenas $1.098(30,5 \%)$ afirmaram que "sim, que sabiam o seu significado", $2.138(59,4 \%)$ responderam que "não" e 361 pessoas $(10,0 \%)$ "não opinaram ou náo souberam responder".

Quando perguntado sobre o conhecimento da existência desses espaços no Município de Manaus, o cenário mudou um pouco, refletindo um grande desconhecimento sobre o assunto pela população entrevistada, quando confrontado com as respostas dadas na pergunta anterior. Dos participantes da pesquisa, $2.769(77,0 \%)$ disseram ou escreveram que "sim", $610(17,0 \%)$ responderam que "não" e 218 (6,1\%) "não opinaram ou não souberam responder".

Em muitas situaçôes tornou-se muito difícil assumir determinadas posturas de forma pública, por um simples mais significativo fator: vergonha ou medo de responder errado diante do investigador/pesquisador.

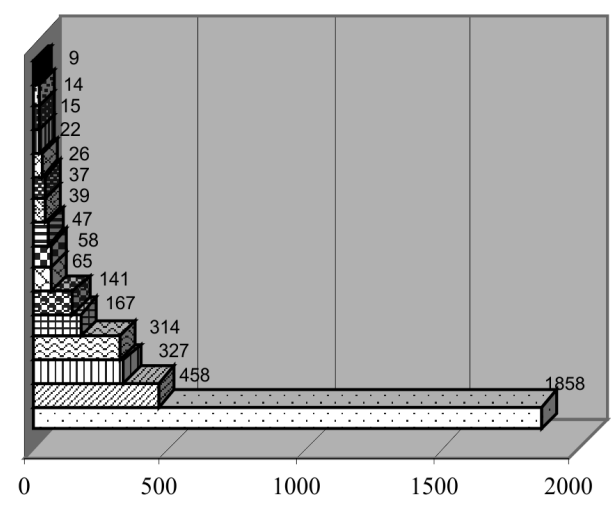

Quando perguntado aos entrevistados sobre quais seriam os principais objetivos da uma Área Natural Protegida ou de uma Unidade de Conservaçáo, as respostas variaram bastante. Do total de entrevistados, 677 pessoas $(18,8 \%)$ responderam que o objetivo desses espaços era para "lazer"; 663 (18,4\%) para "conservação ambiental"; $538(15,0 \%)$ responderam como "espaço cultural"; 511 (14,2\%) um lugar para a "prática de atividades físicas (caminhadas, passeios de bicicletas etc.)"; $451(12,5 \%)$ responderam que esses locais destinavam-se a um "lugar de encontro do Homem com a Natureza"; 286 $(8,0 \%)$ pessoas responderam que a presença desses espaços contribui para aumento da qualidade de vida da população"; $54(1,5 \%)$ responderam que eram "espaços de meditaçâo"; e, $417(11,6 \%)$ pessoas "não opinaram ou não souberam responder".

Dentre as perguntas, solicitou-se dos entrevistados alguns exemplos de Áreas Naturais Protegidas ou de Unidades de Conservação próximas de seus locais de residência, trabalho e/ ou estudo com a finalidade de se averiguar o reconhecimento, ou até mesmo o conhecimento da populaçáo, visitante ou não visitante, sobre as unidades de conservaçâo estudadas, enquanto áreas naturais que deviam ser protegidas.

O resultado foi surpreendente. Grande parte dos entrevistados não reconhece ou nẫo tem conhecimento sobre as unidades de conservação objetos desse estudo. Isso tanto é verdadeiro, que os exemplos de Áreas Naturais Protegidas ou de Unidades de Conservação mencionados, muitas vezes, estão a quilômetros de distância de suas residências, locais de trabalho ou de estudo. Algumas dessas áreas são beneficiadas pela mídia, enquanto outras nem se quer se configuram como tal ou estáo fora do domínio municipal de Manaus, conforme se observa na Figura 4.
ARIE do Campus da UFAM

⿴囗十 Escola Agrotécnica de Manaus

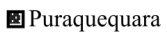

四Horto Municipal de Manaus

Área Verde Conjunto Residencial Castanheiras

운 RDS do Tupé

⿴囗大 Cachoeiras de Presidente Figueiredo

目Tarumã

ÐSIGS

凹Largo de São Sebastião

巴Reserva Ducke

田Complexo de Lazer Ponta Negra

Q Refúgio da Vida Silvestre Sauim Castanheiras

口Bosque da Ciência - INPA

○ Jardim Botânico de Manaus Adolpho Ducke

口Parque Municipal do Mindú

Figura 4 - Exemplos de áreas naturais protegidas ou de unidades de conservação em Manaus, citados pelos entrevistados. 
Solicitou-se ainda aos entrevistados a indicaçáo dos principais problemas ambientais observados em Manaus e, dentre as opçóes apresentadas, procurou-se misturar indicadores de abordagem natural, social e cultural.

As respostas observadas acima concentraram os problemas ambientais de Manaus em 79,2\% nos indicadores naturais (água, lixo, animais, plantas, solo, ar e ruídos) e somente 20,8\% nos indicadores sócio-culturais (prostituição, saneamento básico, planejamento urbano, invasóes de terra, ocupação ilegal de áreas protegidas, consumo e tráfico de entorpecentes e destruição do patrimônio público), observando-se certa contradição com as respostas apresentadas, quando perguntado à mesma população sobre a inserçáo do Ser Humano no contexto ambiental.

Notou-se nesses dados, certa subjetividade e incerteza da inclusão do ser humano, ora como agente ativo e causador dos chamados problemas ambientais, ora como aquele que sofre (agente passivo) a reaçáo da Natureza, como conseqüência do seu próprio desrespeito diante da mesma.

Contraditoriamente, muitos entrevistados atribuíram a causa dos grandes desastres ecológicos ao ser humano, mesmo que não reconhecido tacitamente.

\section{A Participação Pública na Gestão Ambiental}

Nesta terceira e última fase da pesquisa, procurou-se saber da opiniáo pública, o nível de comprometimento que a parcela da sociedade local entrevistada tem sobre a proteção ambiental e a gestáo compartilhada entre Governo e Sociedade.

Em entrevista sobre com quem está a responsabilidade de proteger o Ambiente ou Meio Ambiente, 1.312 pessoas $(36,5 \%)$ alegaram que a responsabilidade está nos "governos"; $917(25,5 \%)$ responderam que está nos "políticos"; 708 (19,7\%) disseram que está nos "cidadãos"; 419 (11,6\%) responderam que isso é competência dos "órgãos ambientais"; e, 241 (6,7\%), que isso "era coisa para os ambientalistas".

Apenas 19,7\% dos entrevistados reconhecem sua responsabilidade frente ao Ambiente. Os demais 79,3\% delegam suas responsabilidades para outras instâncias e instituições.

Quando perguntado sobre a importância da participação social como instrumento para legitimar a proteção das áreas naturais de Manaus, do universo de entrevistas, 1.974 $(54,9 \%)$ das pessoas afirmaram que "sim, a participação dos cidadãos é muito importante"; 1.056 (29,4\%) disseram que "não, a população sozinha não pode fazer nada, isso cabe ao governo e a polícia"; e, $567(15,8 \%)$ "não opinaram ou que não souberam responder".

Com esse resultado, pode-se inferir que há certa consciência sobre a importância da participaçáo da sociedade nas definiçôes das políticas públicas. Porém, observa-se a existência de uma parcela da população entrevistada com certo grau de acomodação, e delegando suas responsabilidades a outrem, e eximido do direito de exercer de fato a sua cidadania.

Esse tipo de resposta, quando as confrontado com a pergunta feita anteriormente, se confirma claramente que, segundo os entrevistados, cabe apenas ao poder público (institucional ou partidário) a defesa pelo ambiente ou meio ambiente.

Quando colocado hipoteticamente uma situação onde os entrevistados tivessem o poder político para criar ou modificar o destino das Áreas Naturais Protegidas ou das Unidades de Conservaçáo de Manaus, do total de entrevistados, $1.643(45,68 \%)$ proporiam a criaçáo de mais unidades de conservação na cidade. Já 1.954 (54,32\%) pessoas proporiam algum tipo de modificação (total ou parcial) nas áreas existentes.

Essa variação em termos de mais ou menos 4,32 pontos percentuais é influenciada pela participação da população jovem, principalmente nas expectativas e carência comunitárias de espaços destinados a diversão e lazer da populaçáo local, as quais propóem a modificação total ou parcial das unidades de conservação em: praças públicas, parques de diversão, shoppings centers e campos de futebol. Uma reprodução dos estilos e formas de vida das metrópoles dos grandes países industrializados e não uma manifestação sócio-cultural autóctone. Estas manifestaçôes implicam a perda de valores etnogeográficos referenciais fortemente enraizados na memória das populaçóes tradicionais, relativos ao relacionamento Homem-Natureza.

Nesse mesmo enfoque, observa-se ainda o clamor das comunidades entrevistadas pelo acesso a itens primordiais ao pleno exercício da cidadania como a educação (escolas), saúde (hospitais) e segurança (policiamento).

\section{CONCLUSÃO}

O estudo partiu da premissa que inferia alguns questionamentos sobre os motivos que levam determinados grupos sociais, a externalizar certas atitudes diante das áreas naturais protegidas, com ênfase na Teoria das Representaçóes Sociais.

Pelo método utilizado no âmbito da pesquisa qualitativa e quantitativa, os resultados foram satisfatórios em funçáo do universo de entrevistas aplicadas para estudo do fenômeno proposto. A abordagem qualitativa buscou a identificação e a interpretação dos fenômenos observados, valorizando a subjetividade e a indução do pesquisador. A abordagem quantitativa, complementar à pesquisa qualitativa, preocupouse em mensurar e constatar tais fenômenos.

Em ambas as situaçóes, os instrumentos utilizados (roteiros, formulários e questionários) procuraram externalizar 
alguns dos aspectos subjetivos do comportamento humano, e as nuances no universo conceitual dos sujeitos entrevistados sobre os fatos do cotidiano, sobre as questôes ambientais e a interaçôes sociais em dado momento temporal, mesmo refletindo algumas indefiniçóes e contradiçóes quando se trata de temas tấo abrangentes como este.

Os cenários atuais, tendencial e normativo das paisagens naturais, modificadas ou mesmo organizadas da área de estudo, quando observados e analisados sob uma ótica investigativa, refletiram essas diversas relações in naturas que vêm ocorrendo de forma dinâmica e com elevadíssimo grau de intensidade e rapidez, traduzida na violenta fragmentaçấo dos ecossistemas naturais pela ação antrópica.

A Educação, em sua amplitude, contínua e permanente, é o instrumento social mais premente para a sensibilização e construção dessa nova sociedade, disposta a rever suas posturas e práticas em prol da qualidade ambiental e de vida da humanidade.

Surpreendentemente, em muitos dos casos observados, a assimilaçáo de certos valores ambientais e a adoção de posturas e práticas adequadas diante do ambiente, independem do nível de escolaridade e dos padróes de vida de determinados grupos sociais.

As decisôes e açôes relacionadas à gestấo ambiental local devem ser empreendidas de forma compartilhada pelos poderes públicos constituídos, pelas organizaçôes governamentais, pelas organizaçôes não governamentais e, principalmente, pela população.

Porém, a participação da população só se concretizará quando a condiçáo sine qua non do acesso a uma Educaçấo Ambiental de forma aplicada, contextualizando o desenvolvimento sustentado à luz do etnodesenvolvimento, valorizando os saberes locais.

O desenvolvimento é como o desabrochar de uma flor, de dentro para fora e nunca de fora para dentro.

\section{BIBLIOGRAFIA CITADA}

Alves-Mazzotti, A. J.; Gewandsznajder, F. 2001. O Método nas Ciências Naturais e Sociais: Pesquisa Quantitativa e Qualitativa. 2a Ediçấo. Pioneira Thomson Learning Ltda., Brasil, 203 pp.

Barros, A. de J. P. de; Lehfeld, N. A. de S. 2004. Projeto de pesquisa: propostas metodológicas. 15a Ediçáo. Petrópolis-RJ: Vozes, 127 pp.

Hogan, D. J. 1993. Crescimento populacional e desenvolvimento sustentável. Revista Lua Nova, São Paulo: Cedec, no 31.

Lakatos, E. M.; Andrade, M. de A. 2001. Fundamentos de metodologia cientifica. 4a Edição rev. ampl. São Paulo-SP: Atlas, 288 pp.

Lincoln, Y. S.; Guba, E. G. 1985. Naturalistic inquiry. Londres: Sage Publications.

Moscovici, S. 1978. .A representaçâo social da psicanálise. PetrópolisRJ: Zahar.

Moscovici, S. 2003. Representaçôes Sociais: investigaçôes em psicologia social. Petrópolis-RJ: Vozes.

Piaget, J. 1969. The mechanics of perception. Nova Iorque: Basic Books.

Reigota, M. 2002. Meio ambiente e representação social. 5a edição. Guarulhos-SP: Cortez, 87 pp.

Wagner, W. 1995. Descrição, explicação e método na pesquisa das representaçôes sociais. In: GUARESCHI, P. A. \& JOVCHELOVITCH, S. (Orgs.). Textos em representaçôes sociais. 8a edição. Petrópolis-RJ: Vozes, p: 149-186.

Recebido em 15/12/2008

Aceito em 29/04/2010 
